\title{
Antibacterial and Energy Gap Correlation of PVA/SA Biofilms Doped With Selenium Nanoparticles
}

\author{
Amr M. Abdelghany 1, *(D), Dalia M. Ayaad 2(D), Sally M. Mahmoud 2 (D) \\ 1 Spectroscopy Department, National Research Center, 33 Elbehouth St, Dokki, Giza 12311, Egypt \\ 2 Chemistry Department، Faculty of Science، Mansoura University، Mansoura 35516, Egypt \\ * Correspondence: a.m_abdelghany@yahoo.com;
}

Scopus Author ID 7003638023

Received: 27.04.2020; Revised: 9.05.2020; Accepted: 9.05.2020; Published: 12.05.2020

\begin{abstract}
Polymeric thin biofilms of polyvinyl alcohol (PVA)/sodium alginate (SA) doped with a different mass fraction of synthesized selenium nanoparticles were successfully synthesized using traditional solution casting routine. Obtained samples were studied for their structural variations using Fourier transform infrared (FT-IR), and ultravilot/visible (UV/Vis.) spectroscopy. FT-IR spectral data reveals the appearance of spectral bands characterized the functional groups of both PVA and SA structural units in their positions. UV/vis. spectral data was employed to calculate the optical energy gap of prepared samples. Antibacterial tests against pathogenic bacteria were performed and correlated to the optical energy gap.
\end{abstract}

Keywords: Polyvinyl alcohol; Sodium alginate; Polymer blend; FTIR; UV/Vis.; Antibacterial tests.

(C) 2020 by the authors. This article is an open access article distributed under the terms and conditions of the Creative Commons Attribution (CC BY) license (https://creativecommons.org/licenses/by/4.0/).

\section{Introduction}

Polymers are found in our daily life details. Due to their unique properties, the polymers industry has spread widely and become one of the most effective industries. Lately, a new concept has appeared and caused a revolution in polymer industries, it is called blending.

A combination of two or more different polymers produces a new material system which is called polymer blend [1-3]. This new material has desirable characteristics than its components so blending is an effective process for improving characteristics of polymeric materials. Natural and synthetic polymers may be combined with different mass fractions to obtain superior materials for specific applications [3]. As the addition of synthetic polymer improves the mechanical characteristics of the natural polymer, as well as its stability and presence of natural polymer, enhance biocompatibility, biodegradability, and hydrophilicity. These blends-in most cases- tend to form hydrogen bonds [1, 3].

Sodium Alginate represents a class of natural polysaccharide that acquired from brown seaweeds [4-7]. It consists of linear chains of $(1,4) \beta$-D-mannuronic acid and $(1,3) \alpha$-Lguluronic acid units. Sodium Alginate has been listed as a safe material by Food and Drug Administration (FDA). So, it is used in food and drinks industry, it also has other various applications; it is used as an emulsifier and gelling agent, thickeners in paint and dye industry and chelator in medical fields $[6,8,9]$, used in the cosmetic industry, textile industry and adhesive pastes $[4,10]$.

Polyvinyl Alcohol is a synthetic linear polymer that prepared via hydrolysis or alcoholysis of polyvinyl acetate under alkaline or acidic conditions [11, 12]. It was first 
prepared in 1924 by W. Herrman and W. Haehel. It is characterized by its good film-forming ability [11], excellent physical properties and high stability due to its high chemical resistance $[4,5,8,11]$. PVA is commonly used by blending with other polymers to improve mechanical properties $[5,8,13,14]$. Its unique chemical and mechanical properties open many fields to be used in as pharmaceutical fields; coating of medicinal tablets, medical fields; making surgical threads and other industries as lacquers, resins, food package materials, paper, textile sizing and as a surfactant in making films and glues [4, 12].

Sodium Alginate is rigid and brittle polymer, so it has poor mechanical properties which can be improved through blending with a synthetic polymer as PVA [8] which has good mechanical properties producing miscible biomaterial with enhanced mechanical characteristics and biocompatibility $[5,7,13]$. Introducing nanoparticles to polymer composite is an interesting technique for many applications $[8,15,16]$.

Selenium is a nonmetallic element that is located in the $16^{\text {th }}$ group in the periodic table. It exists in organic and inorganic forms, it is essential in our daily diet. On the other hand, it has high toxicity if taken with too much dose in the diet. So toxicity of selenium forms hindrance in its applications. But it was found that Selenium nanoparticles are much less toxic than elemental selenium (about 7 times) [17, 18]. SeNP's can be prepared by various methods with high biological activity and photoelectric performance so they have many applications; they are used in solar cells besides many various uses and most commonly used in the medical field as an immunostimulatory agent against different types of cancer [17, 18].

SeNP's tend to agglomerate which decreases stability [16] so before using in any application, they must be stabilized firstly. Coating by polymeric material is a simple technique for stabilizing of SeNPs. As it causes increasing viscosity, reducing interaction between Selenium nanoparticles, decreasing agglomeration and also helping conjugation of nanoparticles with biomacromolecules.

During the present work, composite films of PVA/SA filled with different mass fractions were synthesized and characterized using different characterization techniques and a trail to correlate physical and biological parameters was introduced.

\section{Materials and Methods}

\subsection{Materials.}

Materials used within the preparation process are of pure chemical reagent and used without further purification. Sodium alginate (SA) purchased from Alfa Aesar Co., Polyvinyl alcohol of molecular weight 15000 purchased from MP Biomedicals, Inc., Sodium selenite and Albumin from porcine serum supplied by Sigma-Aldrich Co.

\subsection{Preparation of Selenium nanoparticles.}

$0.2 \mathrm{~g}$ of sodium selenite was stirred with $50 \mathrm{ml}$ bi-distilled water. $0.2 \mathrm{~g}$ of albumin was stirred in $20 \mathrm{ml}$ bi-distilled water. Final obtained solutions were then mixed and placed in a clean autoclave regulated at about $120^{\circ} \mathrm{C}$ for 20 minutes. The Solution of selenium nanoparticles has a reddish color was obtained. 


\subsection{Preparation of PVA/ SA blend.}

The base sample of PVA/SA was prepared by dissolving a pre-calculated equal amount of both polymers separately in bi-distilled water. After the solubility of the polymers, the two solutions were added to each other and stirred at $50{ }^{\circ} \mathrm{C}$ for about $2 \mathrm{~h}$. The obtained mixture was then left to cool to obtain a bubble-free solution with acceptable viscosity and homogeneity. The solution was then poured in a plastic Petri-dish and water evaporates in an oven regulated at $45{ }^{\circ} \mathrm{C}$ for three days. The film was then peeled from the dish and preserved in a dry place until use. The same steps were repeated with different calculated mass fractions of SeNPs to obtain the Se doped samples. Sample notation and composition was introduced in Table 1.

Table 1. Samples notation and composition.

\begin{tabular}{c|c|c|c|c}
\multirow{2}{*}{ Sample notation } & & PVA & SA & SeNPs \\
\cline { 2 - 3 } & & $\mathrm{Wt} \%$ & $\mathrm{Wt} \%$ & $\mathrm{ml}$ added \\
\hline PVA & & 100 & - & - \\
\hline SA & & 0 & 100 & - \\
\hline PVA/SA & & 50 & 50 & - \\
\hline Se2 & & 50 & 50 & $2 \mathrm{ml}$ \\
\hline Se4 & & 50 & 50 & $4 \mathrm{ml}$ \\
\hline Se8 & & 50 & 50 & $8 \mathrm{ml}$ \\
\hline Se16 & & 50 & 50 & $16 \mathrm{ml}$
\end{tabular}

\section{Results and Discussion}

\subsection{Characterization of SeNP's.}

The formation of SeNP's can be cheeked via UV/vis. The spectral analysis which was carried out in wavelength range 200-1100 nm as shown in Figure 1. Obtained solution exhibited absorption maxima at a wavelength around $388 \mathrm{~nm}$ which is the characteristic absorption of SeNP's as reported by different authors [15-18]. Figure 2 shows transmission electron microscopic (TEM) images combined with their selected area electron diffraction (SAED). Drawn data approve the formation of crystalline nano-spheres of diameter ranging between 25$50 \mathrm{~nm}$.

This section may be divided by subheadings. It should provide a concise and precise description of the experimental results, their interpretation as well as the experimental conclusions that can be drawn.

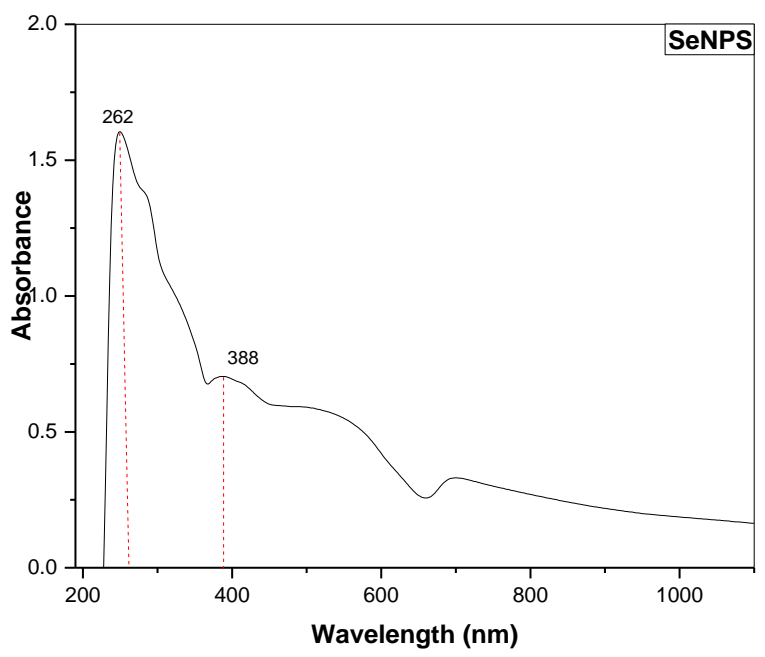

Figure 1. UV/Vis optical absorption spectra of synthesized SeNP's. 

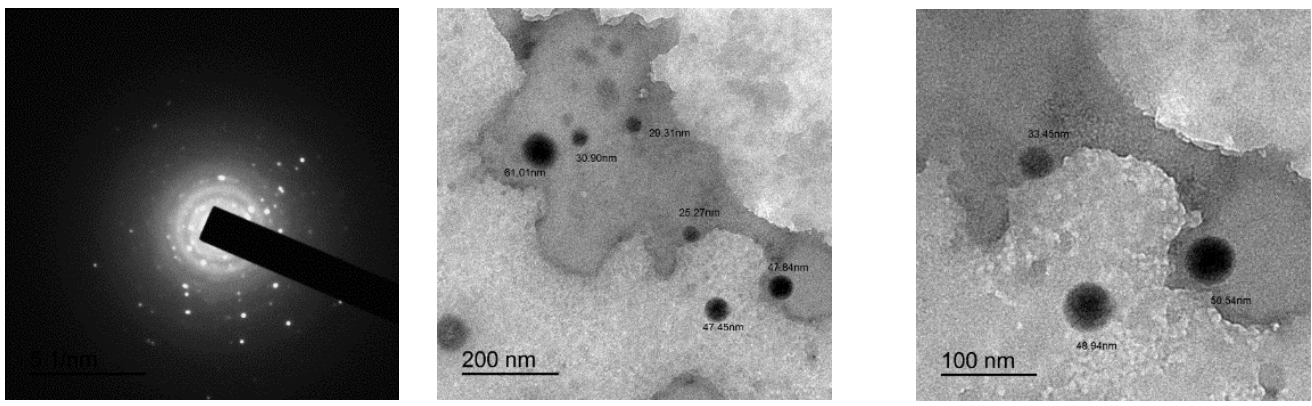

Figure 2. TEM/SAED images of synthesized SeNP's.

\subsection{Fourier Transform Infrared (FTIR).}

FTIR can be considered as one of the most important techniques for the characterization of systems; it provides us with information about the composition of the blend in the addition to interactions between polymers of the blend. Figure 3 shows FTIR spectra for pure PVA and SA and their blend before and after the addition of different concentrations of SeNP's. Different characteristic bands previously reported $[11,14,15]$ for studied polymers were observed in their positions. The bands located at about $3389 \mathrm{~cm}^{-1}$ in the spectrum of SA attributed for $-\mathrm{OH}$ groups, while that at $1610 \mathrm{~cm}^{-1}$ assigned for the symmetric $-\mathrm{COO}^{-}$stretching vibration and at band located at about $1416 \mathrm{~cm}^{-1}$ assigned to the asymmetric $-\mathrm{COO}^{-}$stretching vibration. The bands located at 3338, 2940, $1426 \mathrm{~cm}^{-1}$ assigned for $-\mathrm{OH}$ groups and stretching, bending vibrations of C-H groups respectively.

For PVA/SA blend films, the characteristic band of the two polymers $-\mathrm{OH}$ group at 3338 and $3389 \mathrm{~cm}^{-1}$ was observed shifted to less frequency range $\left(3350 \mathrm{~cm}^{-1}\right)$ in spectra of PVA/SA blend, this indicates hydrogen bonding [4, 6]. It was noticed that absorption bands of the blend are similar to those of the pure components with different intensity. It was observed also that introduction of SeNP's in the previously mentioned concentrations resulted in observed changes both in the position or intensity of the absorption bands of the blend. Peak position and their assignments can be summarized and tabulated as shown in Table 2 [14-16].

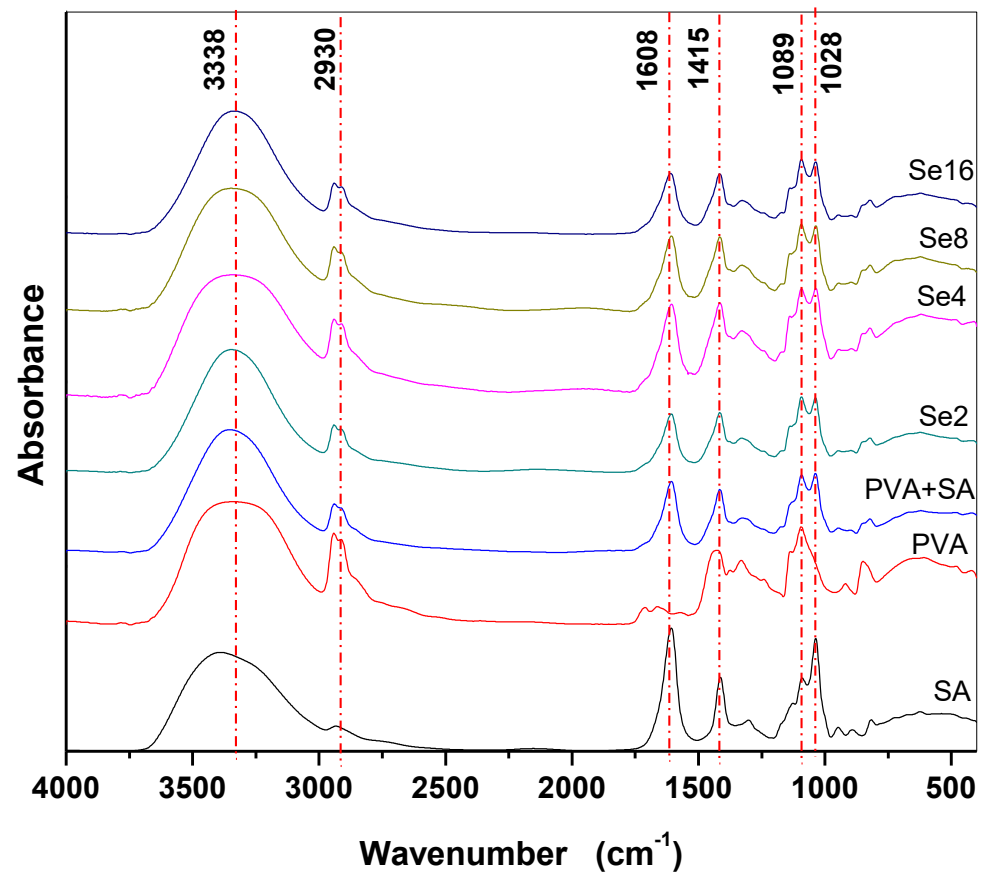

Figure 3. FTIR spectra for PVA/SA blend with different contents of SeNP's. 
Table 2. FTIR band position and assignment.

\begin{tabular}{l|l}
\multicolumn{2}{c}{ Pure PVA } \\
\hline 3338 & -OH group \\
\hline 2940 & Stretching C-H \\
\hline 1426 & Bending C-H \\
\hline \multicolumn{2}{|c}{ Pure SA } \\
\hline 3389 & -OH group \\
\hline 2930 & Stretching -CH \\
\hline 1610 & Symmetric -COOH \\
\hline 1416 & Asymmetric -COOH \\
\hline 1040 & C-O-C group \\
\hline & PVA/SA \\
\hline 3350 & -OH group \\
\hline 2930 & Stretching -CH \\
\hline 1610 & Symmetric -CH \\
\hline 1416 & Asymmetric -CH
\end{tabular}

\subsection{Ultra Violet Visible spectra (UV-Vis).}

UV-Visible spectra for pure samples, pure blend, and blends with SeNPs were measured at a wavelength range of 200-1100 nm. As shown in Figure (4.a) both virgin samples of pure PVA and SA showed absorption bands in the UV region below $250 \mathrm{~nm}$ usually attributed to $\pi$-electron transition and without any additional peaks till the end of measurements. Besides, transparent films of the PVA/SA blend showed a weak absorption band at the shorter wavelength without further peaks to the end of measurements. Figure (4.b) reveals UV/Vis. absorption spectral data of synthesized films before and after the addition of successive amounts of SeNP's. With introducing successive amounts of SeNP's to the (PVA/SA) blend no new absorption peaks were observed. It was noticed that the absorbance of the sample within the visible region increases with increasing SeNP's content. Besides, a red shift in the fundamental absorption edge was also observed indicating a decrease in the optical energy gap associated with increasing SeNP's content within the matrix $[17,18]$.

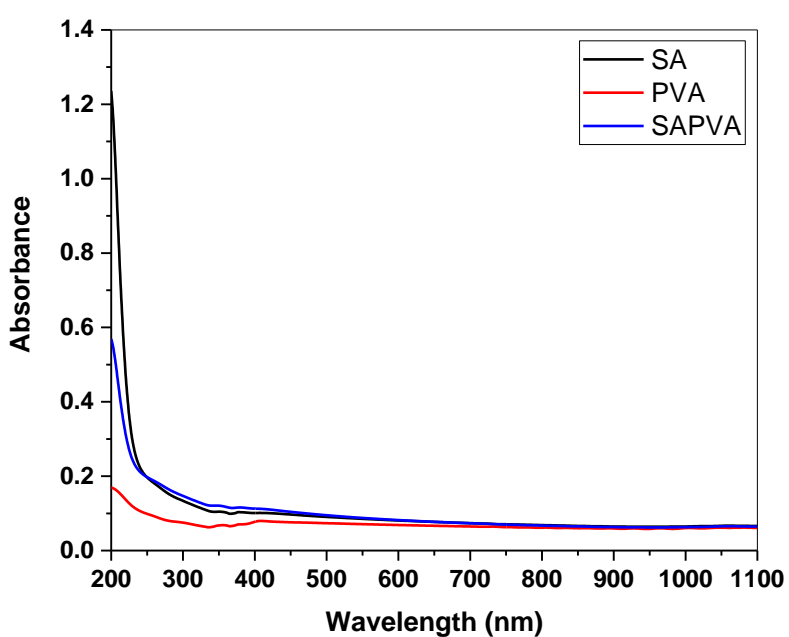

(a)

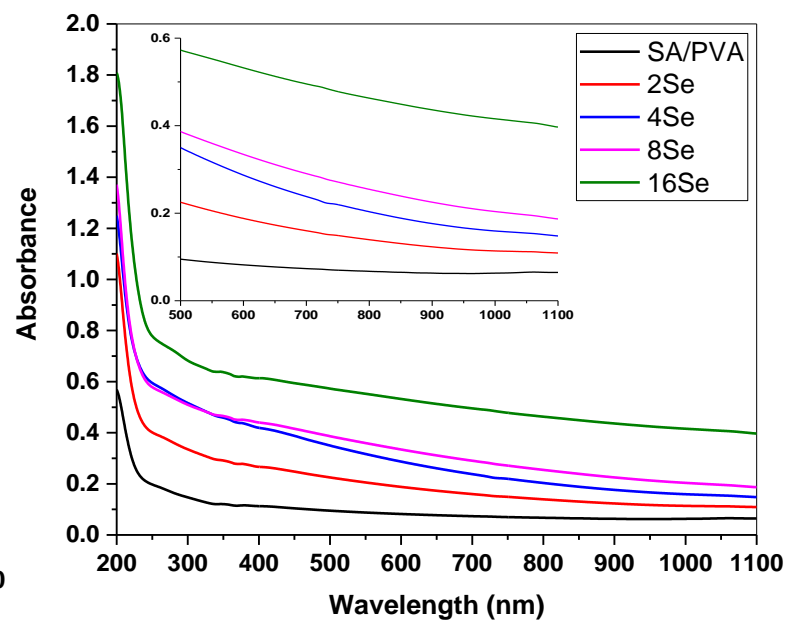

(b)

Figure 4. UV-Vis absorption spectra of SA, PVA virgin samples, and their blend (a) PVA/SA with different contents of SeNPs (b).

\subsection{X-ray diffraction.}

$\mathrm{XRD}$ is used to obtain information about the structure and crystallinity of the prepared samples. XRD patterns were measured within the diffraction angles 5-70 . PVA, SA and their blend are represented in Figure (5.a) shows a sharp board peak located at $2 \theta=19.5^{\circ}$ for pure 
PVA which corresponds to the lattice plane (110) indicating the semi-crystalline nature of PVA. XRD pattern approves also the amorphous structure of the SA. The blending process appears to preserve the semi-crystalline character of PVA as that previously reported by different authors [19-21]. Figure (5.b) represents XRD of pure blend sample in addition to other samples with different concentrations of SeNP's. Recorded spectra indicate that the addition of SeNP's didn't significantly affect the semi-crystalline nature of the blend.

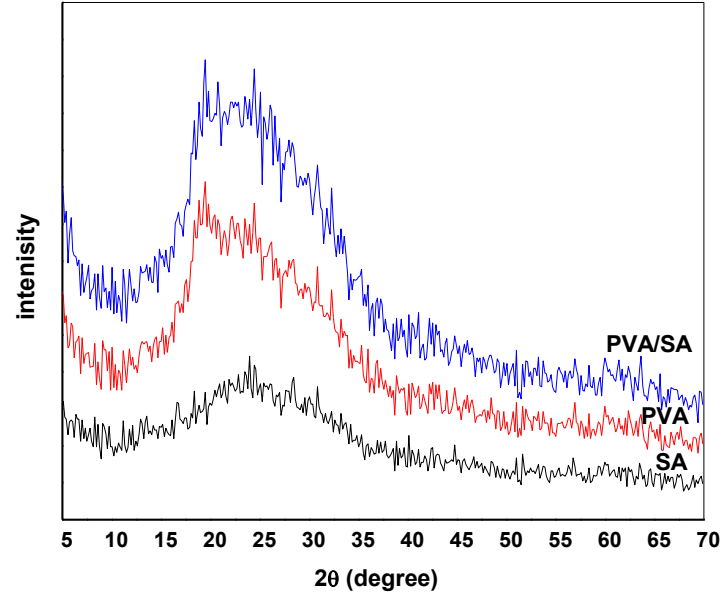

(a)

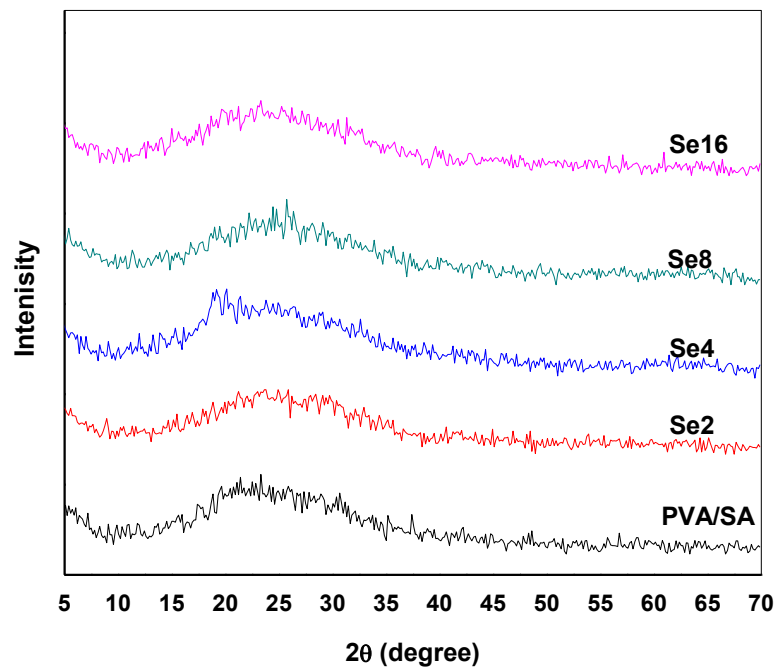

(b)

Figure 5. XRD of studied biofilms. (a) XRD pattern of pure PVA and SA and their pure blend, (b) XRD pattern for PVA/SA blend with different contents of SeNPs.

\subsection{Antimicrobial analysis.}

Antimicrobial activity of pure PVA and SA and their blend with different contents of SeNPs was investigated against Staphylococcus aureus, Bacillus subtilis, Esherichia coli and Pseudomonas aeuroginosa bacteria and Candida albicans Fungus [22, 23]. Table 3 shows the diameter of the inhibition zone of the used microbes. The \% activity index was calculated for the tested samples using the relation:

$$
\% \text { Activity Index }=\frac{\text { Zone of inhibition by test sample }}{\text { Zone of inhibition by standard }} \times 100
$$

Figure 6 shows the variation of antibacterial activity versus SeNP's concentration or optical energy gap within the polymeric network.

Table 3. The diameter of the inhibition zone and \% activity index for PVA/SA blend with SeNPs contents.

\begin{tabular}{|c|c|c|c|c|c|c|c|c|c|c|c|}
\hline \multirow[t]{2}{*}{ No. } & \multirow[t]{2}{*}{ Sample } & \multicolumn{2}{|c|}{ E. coli } & \multicolumn{2}{|c|}{$\begin{array}{c}\text { Pseudomonas } \\
\text { aeuroginosa }\end{array}$} & \multicolumn{2}{|c|}{ S. aureus } & \multicolumn{2}{|c|}{ Bacillus subtilis } & \multicolumn{2}{|c|}{ C. Albicans } \\
\hline & & Dim. & Act. & Dim. & Act. & Dim. & Act. & Dim. & Act. & Dim. & Act. \\
\hline 1 & SA & 7.0 & 17.5 & 8.0 & 17.8 & 5.0 & 20 & 4.0 & 13.33 & -- & \\
\hline 2 & PVA & 4.0 & 10 & 4.0 & 8.89 & 3.0 & 12 & 3.0 & 10 & -- & \\
\hline 3 & S0 & 5.0 & 12.5 & 5.0 & 11.11 & 4.0 & 16 & 4.0 & 13.33 & -- & \\
\hline 4 & S1 & 10.0 & 25 & 9.0 & 20 & 7.0 & 28 & 5.0 & 16.67 & 3.0 & 7.5 \\
\hline 5 & S2 & 13.0 & 32.5 & 13.0 & 28.89 & 8.0 & 32 & 6.0 & 20 & 5.0 & 12.5 \\
\hline 6 & S3 & 15.0 & 37.5 & 16.0 & 35.56 & 10.0 & 40 & 8.0 & 26.67 & 7.0 & 17.5 \\
\hline \multirow[t]{3}{*}{7} & $\mathrm{~S} 4$ & 17.0 & 42.5 & 18.0 & 40 & 12.0 & 48 & 14.0 & 46.67 & 9.0 & 22.5 \\
\hline & Ampicillin & 40 & & 45 & & 25 & & 30 & & & \\
\hline & Colitrimazole & & & & & & & & & 40 & \\
\hline
\end{tabular}




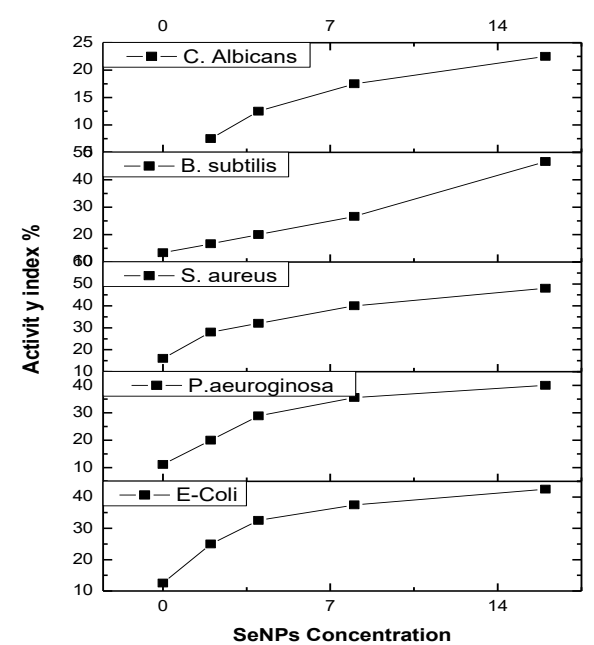

Figure 6. Variation of activity index and content of SeNPs in PVA/SA blend.

Among the studied samples and the different types of the tested bacteria, it was noticed that PVA/SA blend with 8 and $16 \mathrm{ml}$ of SeNPs content had the largest inhibition zones and so the highest antimicrobial activity. From the obtained results it was found that both of inhibition zone and activity index against bacterial [21] and fungal activity increased widely with increasing of SeNP's content in the blend until the content of $8 \mathrm{ml}$ whereby increasing more content of SeNP's causing a slight increase in the activity index so when using PVA/SA blend with SeNP's the content of $8 \mathrm{ml}$ SeNP's is recommended. This antimicrobial activity is due to diffusion through the cell membrane and then interaction with the cell protein leading to its damage. It is known that nanoparticles are the best material increasing diffusion due to their tiny-sized particles so large surface area. So as the content of nanoparticle increases leading to facilitate more diffusion of material through the microbial cell causing faster and more damage to the cell.

\section{Conclusions}

Composite biofilms of semi-natural polymer blend PVA/SA containing gradually increased SeNP's were successfully synthesized via ordinary solution casting route. FTIR spectral data reveals a close similarity of spectral data of the two virgin polymers with that of the blend. SeNP's resulted in observed changes either in the position or intensity of the absorption bands of the blend. UV/Vis. optical absorption data shows the dependence of SeNP's concentration with the optical energy gap. Antibacterial tests against pathogenic bacteria were performed and correlated to the optical energy gap.

\section{Funding}

This research received no external funding.

\section{Acknowledgments}

The authors declare no acknowledgments.

\section{Conflicts of Interest}

The authors declare no conflict of interest. 


\section{References}

1. Paul, D.R.; Barlow, J.W. Polymer blends. J. Macromol. Sci. Rev. Macromol. Chem. Phys. 1980, 18, 109-68, https://doi.org/10.1080/00222358008080917.

2. Jenkins, A.D.; Kratochvíl, P. Stepto, R.F.; Suter, U.W. Glossary of basic terms in polymer science (IUPAC Recommendations 1996). Pure Appl. Chem. 1996, 68, 2287-311, https://doi.org/10.1351/pac199668122287.

3. Abdelghany, A.M.; Menazea, A.A.; Ismail, A.M. Synthesis, characterization and antimicrobial activity of Chitosan/Polyvinyl Alcohol blend doped with Hibiscus Sabdariffa L. extract. J. Mol. Struct. 2019, 5, 603-9, https://doi.org/10.1016/j.molstruc.2019.07.089.

4. Yadav, C.; Maji, P.K. Synergistic effect of cellulose nanofibres and bio-extracts for fabricating high strength sodium alginate based composite bio-sponges with antibacterial properties. Carbohydr. Polym 2019, 396408, https://doi.org/10.1016/j.carbpol.2018.09.050.

5. $\quad$ Dong, Y.Q.; Zhang, L.; Shen, J.N.; Song, M.Y.; Chen, H.L. Preparation of poly (vinyl alcohol)-sodium alginate hollow-fiber composite membranes and pervaporation dehydration characterization of aqueous alcohol mixtures. Desalination 2006, 193, 202-210, https://doi.org/10.1016/j.desal.2005.08.023.

6. Shalumon,, K.T.; Anulekha, K.H.; Nair, S.V.; Nair, S.V.; Chennazhi, K.P.; Jayakumar, R. Sodium alginate/poly (vinyl alcohol)/nano $\mathrm{ZnO}$ composite nanofibers for antibacterial wound dressings. Int. J. Biol. Macromol. 2011, 49, 247-254, https://doi.org/10.1016/j.ijbiomac.2011.04.005.

7. Hemalatha, K.; Somashekarappa, H.; Somashekar, R. Preparation and characterization of MMT doped PVA/SA polymer composites. Advances in Materials Physics and Chemistry 2014, 4, https://doi.org/10.4236/ampc.2014.49020.

8. Eghbalifam, N.; Frounchi, M.; Dadbin, S. Antibacterial silver nanoparticles in polyvinyl alcohol/sodium alginate blend produced by gamma irradiation. Int. J. Biol. Macromol. 2015, 80, 170-176, https://doi.org/10.1016/j.ijbiomac.2015.06.042.

9. Kanimozhi, K.; Khaleel, B.S.; Sugantha, K.V.; Kaviyarasu, K. Development and characterization of sodium alginate/poly (vinyl alcohol) blend scaffold with ciprofloxacin loaded in controlled drug delivery system. $J$. Nanosci. Nanotechnol. 2019, 19, 2493-2500, https://doi.org/10.1166/jnn.2019.16022.

10. Aprilliza, M. Characterization and properties of sodium alginate from brown algae used as an ecofriendly superabsorbent. IOP Conference Series: Materials Science and Engineering, 2017, 188, 012019, https://doi.org/10.1088/1757-899X/188/1/012019.

11. Lang, K.; Sourirajan, S.; Matsuura, T.; Chowdhury, G. A study on the preparation of polyvinyl alcohol thinfilm composite membranes and reverse osmosis testing. Desalination 1996, 104, 185-196, https://doi.org/10.1016/0011-9164(96)00041-0.

12. Gaaz, T. S.; Sulong, A.B.; Akhtar, M.N.; Kadhum, A.A.H.; Mohamad, A.B.; Al-Amiery, A.A. Properties and applications of polyvinyl alcohol, halloysite nanotubes and their nanocomposites. Molecules 2015, 20, 22833-22847, https://doi.org/10.3390/molecules201219884.

13. Caykara, T.; Demirci, S.; Eroğlu, M.S.; Güven, O. Surface properties of binary blend films of poly (N-vinyl2-pyrrolidone) and poly (vinyl alcohol) with sodium alginate. Polym. Sci. B Polym. Phys. 2006, 44, 426-430, https://doi.org/10.1002/polb.20712.

14. Islam, M.S.; Karim, M.R. Fabrication and characterization of poly (vinyl alcohol)/alginate blend nanofibers by electrospinning method. Colloids Surf. A Physicochem. Eng. Asp. 2010, 366, 135-140, https://doi.org/10.1016/j.colsurfa.2010.05.038.

15. Rogovina, S.Z.; Vikhoreva, G.A. Polysaccharide-based polymer blends: Methods of their production. Glycoconjugate J. 2016, 23, https://doi.org/10.1007/s10719-006-8768-7.

16. García, M.C.; Quiroz, F. Nanostructured polymers. In: Nanobiomaterials. Woodhead Publishing, 2018 ; pp. 339-356, https://doi.org/10.1016/B978-0-08-100716-7.00028-3.

17. Zhang, J.; Wang, X.; Xu, T. Elemental selenium at nano size (Nano-Se) as a potential chemopreventive agent with reduced risk of selenium toxicity: comparison with se-methylselenocysteine in mice. Toxicol. Sci. 2017, 101, 22-31, https://doi.org/10.1093/toxsci/kfm221.

18. Chaudhary, S.; Umar, A.; Mehta, S.K. Selenium nanomaterials: an overview of recent developments in synthesis, properties and potential applications. Prog. Mater. Sci. 2016, 83, 270-329, https://doi.org/10.1016/j.pmatsci.2016.07.001.

19. Elashmawi, I.S.; Abdelghany, A.M.; Hakeem, N.A. Quantum confinement effect of CdS nanoparticles dispersed within PVP/PVA nanocomposites. J. Mater. Sci.: Mater. Electron. 2013, 24, 2956-2961, https://doi.org/10.1007/s10854-013-1197-z.

20. Abdelghany, A.M.; Menazea, A.A.; Ismail, A.M. Synthesis, characterization and antimicrobial activity of Chitosan/Polyvinyl Alcohol blend doped with Hibiscus Sabdariffa L. extract. J. Mol. Struct. 2019, 1197, 603-609, https://doi.org/10.1016/j.molstruc.2019.07.089.

21. Abdelghany, A.M.; Oraby, A.H.; Farea, M.O. Influence of green synthesized gold nanoparticles on the structural, optical, electrical and dielectric properties of (PVP/SA) blend. Physica B: Condensed Matter 2019, 560, 162-173, https://doi.org/10.1016/j.physb.2019.02.029. 
22. Abdelghany, A M.; Meikhail, M.S.; Abdelraheem, G.E.A.; Badr, S.I.; Elsheshtawy, N. Lepidium sativum natural seed plant extract in the structural and physical characteristics of polyvinyl alcohol. International Journal of Environmental Studies 2018, 75, 965-977, https://doi.org/10.1080/00207233.2018.1479564.

23. Ayaad, D.M.; Abdelaal, M.Y.A.; Aboelkheir, A.M.; Abdelghany, A.M. Performance enhancement of chitosan filled silver vanadate nano-rods. J. Inorg. Organomet. Polym 2019, 29, 901-907, https://doi.org/10.1007/s10904-018-01064-1. 